\title{
Research on Initial Value under the Role of Occupation Based on Curve Fitting
}

\author{
Di Liu \\ Sports Department, Northeast Forestry University, Harbin, China \\ I_iu_di@126.com
}

Keywords: exponential fitting; intermediate variables; statistics; high-order md method; initial value problem

\begin{abstract}
Compared with foreign countries, the speed of basketball professionalism in China moves slowly, because of various factors, such as economy, system and regulations, while colleges have many advantages, like adequate site of gymnasium, abundant resources of student voluntary service in a match, these have great impact on basketball professionalism. By investigation and analysis, this paper applies high order exponential fitting in the result of the investigation, and uses college basketball as intermediate variable, uses the basketball environment, court, service as external influence, deeply discusses and analyses the relation between college basketball and basketball professionalism, finally, puts forward related suggestions and countermeasures through analysing and applying colleges' own advantages, and provides theoretical reference and basis for developing basketball professionalism in college, and training high-level athletes and coaches.
\end{abstract}

\section{Introduction}

In China, the progress of basketball professionalism faces many obstacles because of various kind of system and laws and regulations, some basketball clubs have been run in deficit for a long time, they can't train excellent athletes and coaches for country[1]. By contrast, college basketball has many exclusive advantages. First, there are adequate resources of basketball gymnasium and training device in college, and can achieve a double breakthrough in both theoretical knowledge and basketball skill. Second, in terms of holding match and service,there are also abundant resources, many student volunteers put themselves into the service of match annually, it provides access to basketball professionalism[2]. Third, college basketball coaches can attract professional basketball coaches, then exercise professionalized training through recruiting basketball players with high quality to make athletes approach to professionalized level[3]. Colleges have great advantages towards basketball professionalism, colleges are not bound by various systems, its progress of training can not be blocked by some objective factors and the development of basketball professionalism can not be blocked by training site or match service, either. Through investigation and statistical analysis[4,5].This paper applies graphical analysis and curve fitting in its result, and finally comes to the relation between college basketball and basketball professionalism, and the promoting relation of college basketball towards basketball professionalism, offers guidance for the development of basketball professionalism and training professional basketball players by suggestions and strategies.

\section{The Present Situation of Athletics Basketball Professionalism}

In China, the basketball professional level is not high, the development of basketball career is restrained by various factors, including economy, system, consciousness, regulation[6].To this, a questionnaire survey about basketball professionalism is held to professional basketball coaches. After analysing the result of investigation, comes to figure1, the findings of basketball professionalism factors.

\begin{tabular}{|c|c|c|}
\hline TABLE I. THE QUESTIONNAIRE OF BASKETBALL PROFESSIONALISM FACTORS \\
\hline Factors & Number of People & 100 \\
\hline Economic environment & 19 & 78.9 \\
\hline System Factor & 15 & 57.9 \\
\hline Consciousness & 11 & 84.2 \\
\hline Regulation construction & 16 & Percentage \\
\hline
\end{tabular}

It can be seen from the figure, most of people feel that legislative degree of basketball professionalism is not high. A perfect law can offer guarantee for development of basketball career, 
one the one hand, legislation makes coaches offer training and competition opportunities to basketball players fairly, on the other hand, the misjudgment from referee in a match and the problem of players competing negatively can be well improved through legislation. But legislation can influence the development of basketball professionalism to some degree, there will be a certain degree of limitations in many aspects. Therefore, it should be careful with regard to the legislation of basketball career, relevant laws and regulations must be cautious and normative, inappropriate use can restrict the development of basketball professionalism. Basketball professionalism is inseparable from basketball match, the degree of satisfaction reflects the level of basketball professionalism to a large extent[7]. The investigation and analysis are held among spectators, coaches and players, then draw a pie chart of the satisfaction degree of everyone on the basketball match, like Figure 1 shown, it can be seen from figure1 that the degree of satisfaction of basketball service is not high in a basketball professional league.

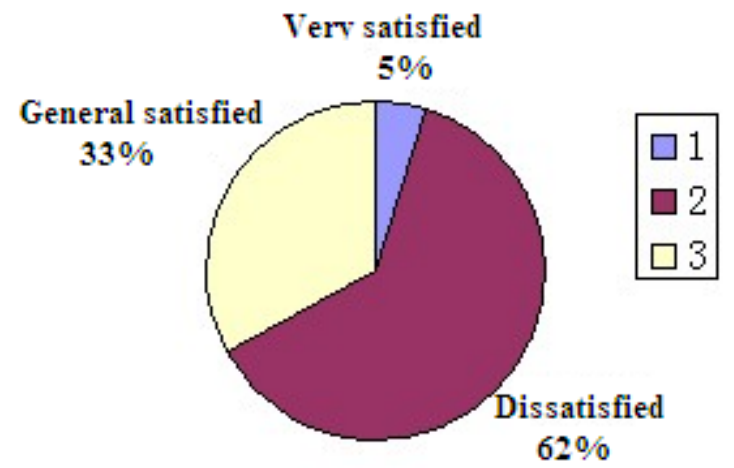

Figure 1. The degree of satisfaction of basketball service

\section{The Present Situation of Colleges Professional Athletics Basketball}

At present, most students love and chase after college basketball sports, this kind of atmosphere provides great conditions for the introduction of excellent basketball coaches, many outstanding coaches who love campus atmosphere and sports which receive ranking in many megagames start to enter the teaching system of colleges basketball[8].This provides technical support for professional basketball training. Colleges have wonderful skill and skill theory research atmosphere, it is in favor of communication of basketball skills, makes colleges professional training techniques and skills are even exceeding some professional club, provides technical communication platform for cultivation of excellent basketball players. By investigation and analysis, this paper this paper applies high order exponential fitting in the result, here is the introduction of higher order exponential fitting. High order MD method can be used in curve fitting.

About initial-value problem,we can establish)the following model[9]:

Set $\mathrm{P} \in \mathrm{D}$, inductive definition[10]:

$$
\left\{\begin{array}{l}
\mathrm{P}^{\prime}=\mathrm{f}(\mathrm{t}, \mathrm{P}(\mathrm{t})), \mathrm{t} \geq 0 \\
\mathrm{P}(0)=\mathrm{a} 0, \text { ao } \in \mathrm{D}
\end{array}\right.
$$

$$
\begin{gathered}
\mathrm{P}^{(0)}=\mathrm{P}, \mathrm{P}^{(1)}=f(t, P), \\
\mathrm{P}^{(\mathrm{i})}=\frac{\partial P^{(i-1)}}{\partial t}+\frac{\partial P^{(i-1)}}{\partial P} * P^{(1)}, \mathrm{i}=2,3, \ldots . .
\end{gathered}
$$

Set $\mathrm{x}=2 \mathrm{p}$, we can get the following[11]:

$$
\left\{\begin{array}{c}
\sum_{q=0}^{l}(-1)^{q}\left(\begin{array}{l}
l \\
q
\end{array}\right)(2 p-q)_{p}=(2 p-l), l=1,2, \ldots, p \\
\sum_{q=0}^{p}(-1)^{q}\left(\begin{array}{l}
l \\
q
\end{array}\right)(2 p-q)_{p}=0, l=1,2, \ldots, p
\end{array}\right.
$$

Set

$$
a_{q}=(-1)_{q_{-1}} b_{q}=\frac{(-1)^{(q-1)}}{q !} \frac{(p)_{q}}{(2 p)_{q}}, q=1,2, \ldots, p,
$$

We can get the following[12]: 


$$
\left\{\begin{array}{c}
\frac{a 1}{(l-1) !}+\frac{a 2}{(l-2) !}+\ldots+a l+b l=\frac{1}{l !}, l=1,2 \ldots, p \\
\frac{a 1}{(l-1) !}+\frac{a 2}{(l-2) !}+\ldots+\frac{a_{P}}{(l-P) !}=\frac{1}{l !}, l=P+1, P+2 \ldots, 2 p
\end{array}\right.
$$

\section{The Role of Colleges in Basketball Professionalism in China}

A. Train Theoretical and Skilled Basketball Professional Player

At present, the training of professional basketball player is limited to a relatively narrow range, such as national team and province team. Many professional trainings focus on match, ignore theories of knowledge and skills training, so that many player who achieved good ranking in match can't find a suitable job after leaving professional career. There are also some basketball players remain at a player only and can't become a coach because they lack of theory and skills. Colleges provide great theoretical research and communication platform for basketball professionalism, many basketball players can not only get contact of basketball physical quality, but also can master one or more basketball vocational skills. Be familiar with a skill theoretically and technically, it is very helpful to whether competing in a match or being engaged in work.

\section{B. Select Professional Basketball Talent}

Colleges generally aim at cultivating talents, take advantage of the talent introduction platform, colleges can attract those excellent talents who possess basketball sports quality, make use of basketball sports resource in college, take professional training to basketball players. This requires that the principle of publicity and equity should be followed when colleges are introducing basketball talents, not only select physical qualified basketball players, but also the basis of the theory and technology should be required, for the preparation of later training.

\section{Basketball Match Event}

There are many matches in colleges, because colleges own a serious abundant resources, such as gymnasium and student voluntary service, the advantage of this kind of resource makes the basketball match event step into colleges constantly. Expect for competitions that colleges hold on their own, CUBA makes college basketball move towards professionalism, many coaches in national team or province team could elect talents from basketball match which is held in colleges. The most obvious feature of basketball match held in colleges is the team of voluntary service is huge, and there is also a lot of sponsor from different social sectors, the degree of satisfaction can not decreased because of economic system. Therefore, colleges should be encourage to hold more associate event to make all different social sectors to focus on basketball sports in colleges, provide realistic possibility for training professional basketball players.

\section{Suggestions and Countermeasures Focus on College Basketball Professionalism}

\section{Improve the Structure and Regulation of Basketball Event}

Because colleges have the advantage of theory communication and research, a research about basketball event system and regulation should be carried out by making use of this advantage, such as mistake of penalty from referee and players compete negatively, all these need some regulations to restrain, welfare and benefits of players and coaches, how does the income should be distribute reasonably to mobilize the enthusiasm of players and coaches. The formulation of system and regulation should be noticed, if the formulation is not appropriate, it will restrain the level of basketball professionalism development. So colleges should put time into researching the flexibility of basketball laws and regulations, formulate appropriate laws and regulations on the development of basketball professionalism

Strengthen the Study of Professional Basketball Theory and Skill

Professional basketball requires players should have not only experience and quality in competing in a match, but also master some certain technical skills, such as technical shooting skills and defensive skills. These skills need not simply repetitive training everyday, but require that players should possess some certain of theoretical skill, apply own skills into basketball match by technical attack and defence.

\section{Increase Basketball Match Events}

Colleges own adequate resource of gymnasium and voluntary service, they can hold more competition events spontaneously under this kind of advantage, this provides a display platform for the development of basketball professionalism and selection of professional basketball talents. Colleges can hold more league matches jointly, and it can makes colleges are on a development path 
on basketball professionalism. Basketball players can obtain plenty of exercise, coaches can also select right talents, and make basketball professionalism with full development.

Cultivate More Excellent Professional Basketball Players Positively

Colleges have great advantage in cultivating basketball players, firstly, they own high-quality training device and outstanding coaches, secondly, they own adequate training site and theory research space. Therefore, colleges should elect more gifted excellent basketball players industriously, and hold professional training, strengthen professional basketball physical training at ordinary times and cultivation of basketball theory and skill, endeavour to cultivate excellent and qualified professional basketball players for country.

\section{Conclusion}

This paper obtains the development of basketball professionalism is restricted by several aspects of factors, such as economy, system, consciousness and legislation through investigation and analysis of basketball professionalism, applies high order exponential fitting in the result of the investigation, and uses college basketball as intermediate variable, the basketball environment, court, service as external influence, deeply discusses and analyses the relation between college basketball and basketball professionalism, finally, puts forward related suggestions and countermeasures through analysing and applying colleges' own advantages, and provides theoretical direction for cultivating high-level players and coaches, and cultivating more talents for colleges basketball professionalism.

\section{Acknowledgments}

This research was supported by the Humanities and social sciences projects in the Education Department of Heilongjiang Province with the project number 12522144 and the project name The Current Situation and Talent Training Mode of College Basketball Players in Heilongjiang from the Qualifier Game of 14th CUBA.

\section{References}

[1] Zhou Qinggong. Analysis and Countermeasure of Decades of Development in China Professional Basketball Club. Sports and Science, 2011,26(2):64-67.

[2] Liu Anqing. Research on Countermeasures of General Colleges High-level Basketball Team Coaches Team Present Situation and Development.. Journal of Beijing Sport University, 2008(11):45-48.

[3] Song Zhenzhen. Discuss on Countermeasures of the Development of Colleges High-level Sports Team from Comparison between CUBA and NCAA. Journal of Shanghai Sport University, 2008(11):11-14.

[4] Yang Tieli. Professional Market Basketball Theory. Beijing: Beijing Sport University Press, 2009.153-165.

[5] Song Jianrong. Explore the Countermeasures of Scientific Management and Development of Basketball Professionalism in China. Longyan College, 2011,23(3): 108-110.

[6] Yang Liusuo, Gao Songshan. Explore and Analysis of Performance and Existing Problem on China Basketball Professionalism Path. Journal of Beijing Sport University, 2011. 27(4): 55-57.

[7] Gong Yaokun, Li Kai, Wang Dong. Some Thinking about Development Strategy of Basketball Professionalism in China. Journal of Jilin Sport University, 2009, 20 (2): 48-49.

[8] Liulan, Li Zhenzhong, Huanglin. Basketball Development Mode with Chinese Characteristics. Journal of Hunan Institute of Humanities Science and Technology College, 2009 (6): 96-99.

[9] Wang Wei, Ding Jianqiao. The Development of Basketball Professionalism and Cultivation of Basketball Reserve Force in China. Martial Science, 2010,1 (6): 78-80.

[10] Chen Jun, Shi Yan. Research on Countermeasures of Achieve Basketball Professionalism Sustainable Development in China. Journal of Beijing Sport University, 2012,25(3):30-35.

[11] Chen Jun, Liu Yiqun. Initial Construction of China Basketball Professionalism Sustainable Development Theoretical Framework. Journal of Guangzhou Sport University, 2012,22(3):2123.

[12] Chen Jun, Sun Minzhi. The Enlightenment of American Basketball Professionalism Cause and Development Gives Us. Journal of Xi'an Sport University, 2012,19(4):65-67. 